\title{
Endovascular Occlusion of Basilar Bifurcation Aneurysms With Electrolytically Detachable Coils
}

\author{
Gary Redekop, Robert Willinsky, Walter Montanera, Karel TerBrugge, \\ Michael Tymianski and M. Christopher Wallace
}

\begin{abstract}
Object: To describe the clinical and angiographic results of endovascular occlusion of basilar bifurcation aneurysms with electrolytically detachable coils, and to identify factors which should be considered in deciding upon surgical or endovascular treatment. Methods: We report our experience with 40 patients in whom occlusion of basilar bifurcation aneurysms with electrolytically detachable coils was attempted. All patients underwent superselective angiography and attempted embolization with Guglielmi detachable coils (GDCs). Angiographic and clinical results were prospectively recorded. Twenty-eight aneurysms presented with subarachnoid hemorrhage (SAH), 2 were symptomatic and 10 were incidental. Results: Coils were not placed in 10 patients $(25 \%)$ because of unfavorable anatomy. Complete aneurysm occlusion was achieved at the time of the initial procedure in $13(32.5 \%)$, small neck remnants were present in 13 $(32.5 \%)$, and in $4(10.0 \%)$ there was obvious residual contrast filling of the aneurysm body. Of 23 patients successfully coiled after SAH, 20 were Grade 1 to 3 and 3 were grade 4 or 5 at the time of treatment. Eighteen (78\%) made a good recovery. Procedural mortality was $2.5 \%$ and permanent morbidity was $7.5 \%$. There were no permanent complications in patients with unruptured aneurysms. Complete aneurysm occlusion was possible in $10(56 \%)$ of 18 aneurysms with small necks and $3(14 \%)$ of 22 with large necks. Follow-up angiography in 25 of 28 surviving patients (mean, 12 months) demonstrated stability of all completely occluded aneurysms. Incompletely coiled aneurysms had variable results on follow-up angiograms: $15.4 \%$ improved, $69.2 \%$ worsened, and $15.4 \%$ were stable. No aneurysm bled after treatment during clinical follow-up averaging 22 months. Conclusions: Endovascular treatment of basilar bifurcation aneurysms appears to prevent early aneurysm rebleeding with acceptable rates of morbidity and mortality, but long-term follow-up is required.
\end{abstract}

RÉSUMÉ: Occlusion endovasculaire d'anévrismes de la bifurcation basilaire au moyen de spires électrolytiquement détachables: observations et résultats cliniques et angiographiques. Sujet: Nous décrivons les résultats cliniques et angiographiques de l'occlusion endovasculaire d'anévrismes de la bifurcation basilaire au moyen de spires électrolytiquement détachables et nous identifions les facteurs dont on devrait tenir compte dans le choix d'un traitement chirurgical ou endovasculaire. Méthodes: Nous rapportons notre expérience chez 40 patients chez qui une tentative d'occlusion d'anévrismes de la bifurcation basilaire au moyen de spires électrolytiquement détachables a été tentée. Tous les patients ont subi une angiographie supersélective et une tentative d'embolisation au moyen de spires détachables de Guglielmi. Les résultats angiographiques et cliniques ont été recueillis de façon prospective. Le mode de présentation chez 22 patients était celui d'une hémorragie sous-arachnoïdienne (HSA), 2 patients étaient symptomatiques et il s'agissait d'une trouvaille fortuite chez 10 autres patients. Résultats: Une spire n'a pas été utilisée chez 10 patients (25\%) parce que l'anatomie ne le permettait pas. Une occlusion complète de l'anévrisme a été obtenue au moment de la procédure initiale chez 13 patients (32.5\%), un petit col résiduel était présent chez $13(32.5 \%)$ et il existait un remplissage résiduel évident du corps anévrismal chez 4 (10.0\%). Parmi les 23 patients chez qui l'intervention a été un succès, 20 étaient de grade 1 à 3 et 3 étaient de grade 4 ou 5 au moment du traitement. Dix-huit (78\%) ont bien récupéré. La mortalité attribuable à l'intervention a été de $2.5 \%$ et la morbidité permanente a été de $7.5 \%$. Il n'y a pas eu de complication permanente chez les patients ayant un anévrisme non rupturé. Une occlusion complète de l'anévrisme a été possible chez 10 des 18 patients (56\%) dont l'anévrisme avait un col étroit et chez 3 des 22 patients (14\%) dont l'anévrisme avait un col large. Une angiographie de contrôle chez 25 des 28 patients survivants, faite en moyenne à 12 mois de suivi, a démontré la stabilité de tous les anévrismes complètement occlus. Quand l'occlusion était incomplète, les résultats étaient variables à l'angiographie de contrôle: $15.4 \%$ étaient améliorés, $69.2 \%$ avaient empiré et $15.4 \%$ étaient stables. Aucun anévrisme n'a saigné après le traitement au cours d'un suivi clinique moyen de 22 mois. Conclusions: Le traitement endovasculaire des anévrismes de la bifurcation basilaire semble prévenir une récidive précoce du saignement avec des taux de morbidité et de mortalité acceptables. Un suivi à long terme déterminera l'efficacité de l'occlusion partielle et complète par une spire quant à la stabilité anatomique et à la prévention d'hémorragies tardives.

Can. J. Neurol. Sci. 1999; 26: 172-181

Management strategies and therapeutic options for the treatment of aneurysms arising at the terminal bifurcation of the basilar artery have evolved considerably over the past decades. Because of their deep and confined location, as well as their intimate relation to cranial nerves and brainstem perforating vessels, the potential for surgical complications is higher than for most other aneurysms. ${ }^{1-5}$ The overall prognosis for ruptured aneurysms in this location is poor. ${ }^{6-8}$ A shift to early surgical clipping has decreased the incidence of recurrent hemorrhage and simplified the management of delayed ischemic complications due to vasospasm, but the benefits of early

From the Departments of Medical Imaging and Surgery, The Toronto Hospital, Toronto, Canada.

RECEIVED NOVEMBER 18, 1998. ACCEPTED IN FINAL FORM APRIL 21, 1999 Reprint requests to: Dr. Gary Redekop, 323-C, 700 West 10th Avenue, Vancouver, British Columbia, Canada V5Z 4E5 
intervention are offset to some extent by the difficulties encountered in operating on a swollen brain. ${ }^{3,9,10}$

Since the initial reports by Guglielmi et al. ${ }^{11,12}$ of an endovascular approach using electrolytically detachable coils, this technique has become widely accepted as an alternative to surgical clipping for patients who are poor surgical candidates or whose aneurysms are felt to carry unusually high risk. ${ }^{13-17}$ While direct surgical clipping is still regarded as the optimal method of permanent aneurysm obliteration, the absence of brain retraction and cranial nerve manipulation with the endovascular technique, and the relative ease of microcatheter access to the vertebrobasilar circulation, make this approach an attractive alternative for basilar bifurcation aneurysms, where microsurgical treatment is particularly difficult.

Recent reports have documented promising early results for basilar bifurcation aneurysms treated with electrolytically detachable coils. ${ }^{18-24}$ Early recurrent hemorrhage of acutely ruptured aneurysms has been prevented, with procedural risks that compare favorably to surgical series. However, many aneurysms treated with this technique have residual neck remnants, and long-term clinical and anatomical effectiveness of endovascular coil occlusion for these aneurysms has not yet been demonstrated. ${ }^{25}$ In this report, we present our experience at a single institution using electrolytically detachable platinum coils for the treatment of basilar bifurcation aneurysms.

\section{Clinical Material and Methods}

\section{Patient Population}

Between February 1993 and December 1997, forty patients underwent attempted endovascular occlusion of basilar bifurcation aneurysms with Guglielmi detachable coils (GDCs, Target Therapeutics, Fremont, CA) at The Toronto Hospital. All patients were referred by neurosurgeons for consideration of endovascular therapy. During this time period, fifteen patients underwent craniotomy and surgical clipping of basilar bifurcation aneurysms. Apart from anticipated surgical difficulty due to location of the aneurysm, indications for endovascular treatment were previous failed surgery in two, advanced age in five, poor clinical grade in five, and severe coronary artery disease in one. The patients in this series represent a select subgroup of all patients with basilar bifurcation aneurysms that were felt to be appropriate for endovascular occlusion with GDCs upon review of initial diagnostic angiograms by an interventional neuroradiologist. Angiographic and clinical parameters were recorded prospectively in a computer database. This analysis includes all patients who underwent superselective microcatheterization and attempted coil placement, even if no coils were detached.

There were 24 females and 16 males, ranging in age from 31 to 81 years, with a mean age of 51.5 years. Twenty-eight patients (70\%) presented with subarachnoid hemorrhage (SAH), ten (25\%) had aneurysms that were identified incidentally, and two (5\%) were symptomatic due to mass effect. Endovascular therapy following SAH was undertaken within 3 days of the bleed in 16 patients $(57 \%)$ and within the first week in 21 patients $(75 \%)$. Patients were classified according to the scale of Hunt and Hess ${ }^{26}$ at the time of treatment. Eleven patients $(27.5 \%)$ were grade 1 ; five $(12.5 \%)$ were grade 2 ; seven $(17.5 \%)$ were grade 3 , four (10\%) were grade 4 ; and one $(2.5 \%)$ was grade 5.

\section{Aneurysm Characteristics}

All patients underwent routine selective angiography as well as dynamic rotational angiography ${ }^{27}$ prior to superselective microcatheterization. Aneurysm size was calculated by measuring the longest dimension of the sac, with reference to a scalp marker and correction made for magnification. Twenty-seven aneurysms $(67.5 \%)$ were $10 \mathrm{~mm}$ or less and thirteen $(32.5 \%)$ were 11 to $20 \mathrm{~mm}$. There were no partially thrombosed or giant aneurysms. The size of the neck was classified according to the projection showing its maximum width. For the purposes of this study we defined an aneurysm neck as being wide if it measured more than $4 \mathrm{~mm}$ in diameter, or, in the case of aneurysms with a maximum size of $4 \mathrm{~mm}$ or less, a sac:neck ratio of less than one. Using these criteria, 18 aneurysms (45\%) had small necks and 22 (55\%) had wide necks.

\section{Endovascular Treatment}

All procedures were performed under general anesthesia in a dedicated neuroangiographic suite with digital subtraction and roadmapping capabilities. Systemic anticoagulation with a bolus of $100 \mathrm{IU} / \mathrm{kg}$ of heparin administered intravenously was initiated as soon as the femoral arterial sheath was inserted, followed by intermittent infusion titrated to maintain the activated clotting time at least two times the baseline value. A 5- or 6-French guiding catheter was positioned distally in the dominant vertebral artery and a microcatheter introduced into the aneurysm sac under digital roadmapping fluoroscopy. Aneurysm occlusion was achieved with GDCs of various lengths and helical diameters, with preference given to 0.010 -in coils (GDC-10) for acutely ruptured aneurysms. At the termination of endovascular therapy the heparin infusion was discontinued but not reversed. Patients with ruptured aneurysms underwent repeat angiography one week after treatment to document vessel patency and degree of aneurysm occlusion and were treated aggressively for vasospasm with hypertensive, hypervolemic therapy and angioplasty as required. Angiographic follow-up was performed or will be performed in all patients approximately 6 months post-treatment, 1 year posttreatment, and thereafter at appropriate intervals based on the degree and stability of aneurysm occlusion.

\section{Results}

\section{Angiographic Outcome}

Coils were successfully detached within the aneurysm sac in 30 patients $(75 \%)$. In 10 patients $(25 \%)$, technical limitations prevented successful coil delivery. Eight failures occurred because of unfavorable aneurysm geometry or a wide neck which allowed a coil positioned within the aneurysm to herniate into the parent vessel, while in two others stable positioning of the microcatheter in the aneurysm sac could not be achieved because of marked tortuosity of the vertebral or basilar arteries. In some of these cases a partial occlusion might have been obtained, with substantial residual aneurysm neck filling, but it was felt that definitive surgical clipping represented a better alternative, particularly in the setting of SAH. Nine of the aneurysms which were not successfully treated were $10 \mathrm{~mm}$ or less in maximum size.

Of the aneurysms which were successfully treated, complete aneurysm occlusion was achieved at the time of the initial 

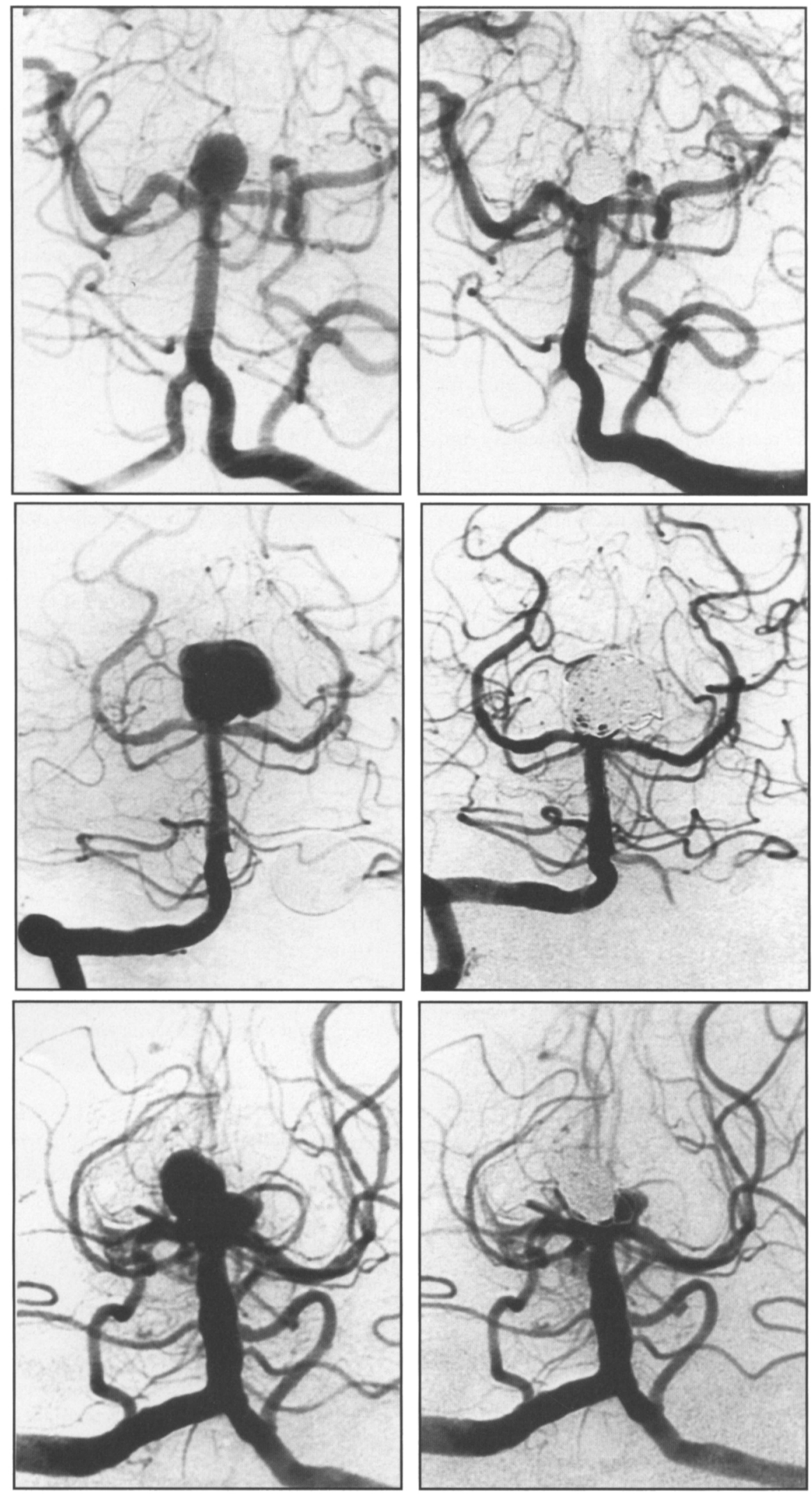

Figure 1: Angiograms obtained immediately before (left) and after (right) endovascular aneurysm occlusion with GDCs, representative of angiographic outcome categories. Top row, complete aneurysm occlusion. Middle row, small neck remnant. Bottom row, bilobed aneurysm with obvious residual contrast filling of the aneurysm body. 
Table 1: Initial Angiographic Results of Endovascular Therapy ( $\mathrm{N}=40$ patients).

\begin{tabular}{lcllll}
\hline & N & $\begin{array}{l}\text { Complete } \\
\text { Obliteration }\end{array}$ & $\begin{array}{l}\text { Residual } \\
\text { Neck }\end{array}$ & $\begin{array}{l}\text { Residual Neck } \\
\text { and Body }\end{array}$ & $\begin{array}{l}\text { No Coils } \\
\text { Detached }\end{array}$ \\
\hline Aneurysm Size & & & & & 2 \\
$\leq 5 \mathrm{~mm}$ & 8 & 4 & 2 & 0 & 7 \\
6 to $10 \mathrm{~mm}$ & 19 & 8 & 3 & 1 & 1 \\
11 to $15 \mathrm{~mm}$ & 10 & 1 & 6 & 2 & 0 \\
16 to $20 \mathrm{~mm}$ & 3 & 0 & 2 & 1 & $3^{*}$ \\
Aneurysm Neck & 18 & 10 & 5 & 0 & 7 \\
Small & 22 & 3 & 8 & 4 & \\
Wide & & & & & \\
\hline
\end{tabular}

* Technical failures in 3 small-neck aneurysms included two patients with marked proximal vessel tortuosity and one 3 mm aneurysm with a $2 \mathrm{~mm}$ neck.

procedure in $13(32.5 \%)$, small neck remnants were present in 13 $(32.5 \%)$, and in $4(10.0 \%)$ there was obvious residual contrast filling of the aneurysm body. Representative examples of angiographic outcome categories are illustrated in Figure 1. Complete aneurysm occlusion was possible in twelve $(44.4 \%)$ of 27 aneurysms measuring $10 \mathrm{~mm}$ or less but in only one $(7.7 \%)$ of 13 aneurysms larger than $10 \mathrm{~mm}$. The size of the neck was also an important determinant of angiographic outcome, with complete aneurysm occlusion possible in $10(55.6 \%)$ of 18 aneurysms with small necks but only $3(13.6 \%)$ of 22 aneurysms with wide necks. Considering the 28 patients with SAH, complete aneurysm occlusion was achieved in 9, a small neck remnant remained in 10, residual filling of the aneurysm body was seen in 4 , and in 5 technical limitations precluded coil placement. A summary of the initial angiographic results based on size and neck characteristics for all patients is presented in Table 1.

At least one follow-up angiogram was performed in 25 (89.3\%) of 28 surviving patients after successful GDC treatment. Twelve patients had one follow-up study, seven had two, three had three, and three had four angiograms, with an average time to the last angiographic evaluation of 12 months (range 6 to 25 months). At each follow-up angiogram, the degree of aneurysm occlusion was recorded and note was made of coil compaction or migration. Any change in the amount of residual neck or aneurysm was documented, even if it did not result in a change in the outcome category, such as a small neck remnant on the initial angiogram which increased in size on follow-up, but without filling of the aneurysm body.

Follow-up angiography was obtained in twelve patients with total aneurysm obliteration at the time of initial treatment. In all twelve cases $(100 \%)$, the aneurysm occlusion was permanent, with complete stability of the result. Ten patients with neck remnants had at least one follow-up study. In 8 cases $(80 \%)$ there was some degree of coil compaction with increased contrast filling of the aneurysm base. In two cases the recanalization was substantial requiring repeat GDC packing in one case and surgical clipping in the other (Figure 2). One patient with a neck remnant $(10 \%)$ remained stable and one (10\%) improved to complete aneurysm occlusion on follow-up angiography. Three patients with residual filling of the aneurysm body had angiographic follow-up. In this small group one patient had significant aneurysm regrowth and underwent repeat GDC packing, one remained stable, and one underwent complete aneurysm thrombosis (Figure
3). In both cases of repeat GDC packing the angiographic result was improved but the outcome category was unchanged in comparison to the initial post-treatment angiogram (Figure 4).

\section{Procedural Complications}

Aneurysm perforation occurred in one case, resulting in marked intraventricular hemorrhage. The patient already had an external ventricular drain in place because of acute hydrocephalus and fortunately suffered no deficit as a result. He recovered fully but remains shunt-dependent. One other patient suffered from aneurysm bleeding during endovascular therapy. Thrombosis of the upper basilar artery was noted on control angiography following satisfactory coil packing with a small neck remnant. Thrombolysis with local intra-arterial urokinase was performed, resulting in immediate fatal aneurysm rebleeding. A third hemorrhagic complication occurred as a result of systemic anticoagulation in a poor-grade patient referred from another institution who had suffered an embolic right middle cerebral artery stroke during the initial diagnostic angiogram. Following an unsuccessful GDC attempt, there was significant worsening of his left hemiparesis. An urgent CT scan demonstrated a large hemorrhage into the site of the previous infarct, requiring surgical evacuation.

Intravascular clotting with thrombo-embolic ischemic events occurred in four patients. Three had neurologic deficits lasting for more than 24 hours and CT scan evidence of new infarction. One patient with mild arm weakness recovered fully before hospital discharge, one was moderately disabled at the time of discharge but eventually made a good recovery, and one patient with posterior cerebral artery thrombotic occlusion and thalamic infarction was severely disabled at the time of discharge with later improvement to moderate disability. The fourth thrombo-embolic event was a transient ischemic attack (TIA) consisting of arm weakness which resolved within 24 hours, with no area of infarction identified on CT scan. One patient experienced transient global amnesia lasting less than 24 hours.

There were no complications with permanent morbidity in any patient with an unruptured aneurysm. One patient with a TIA involving the arm recovered fully within 24 hours. Within the group of patients in whom treatment was attempted but unsuccessful, there was one complication, hemorrhage into a previous infarct requiring surgical evacuation. Significant morbidity related to the procedure was one death (2.5\%) and three permanent 

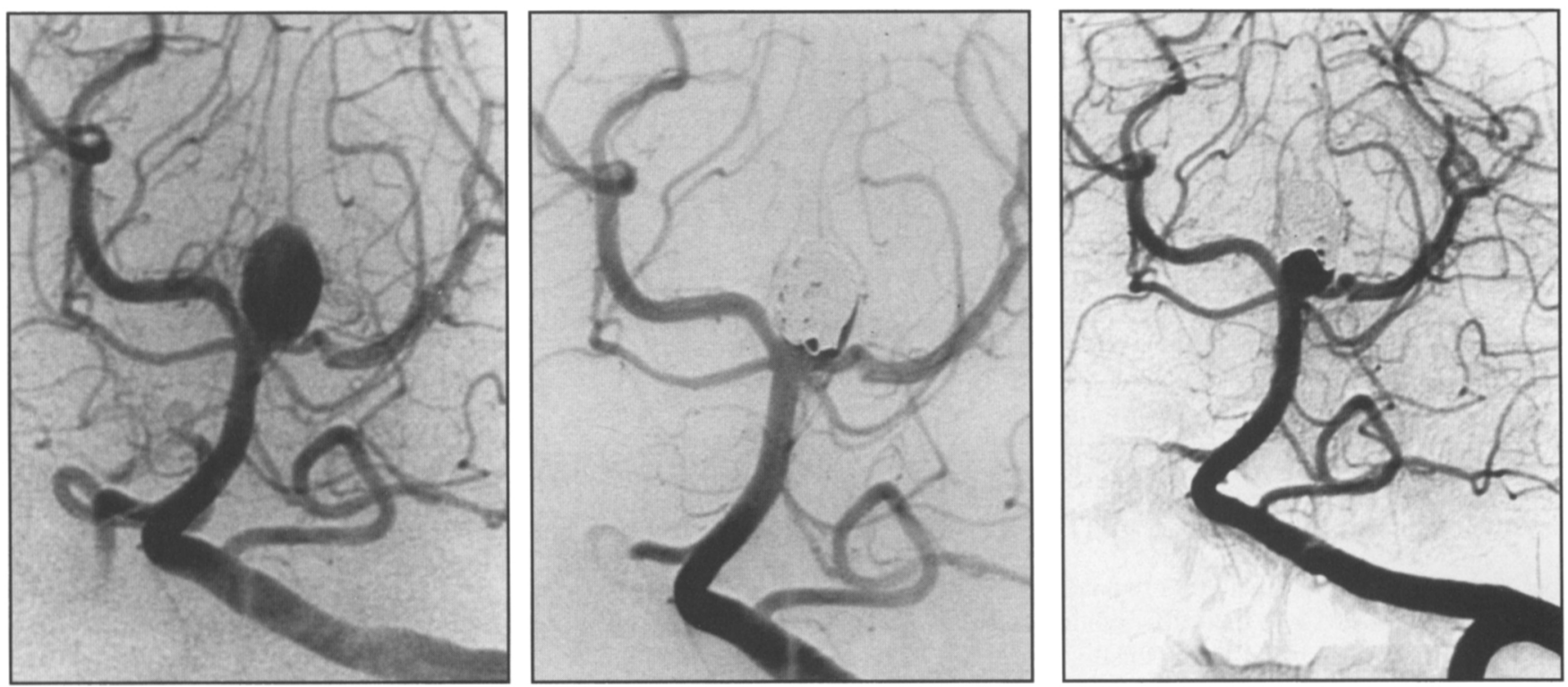

Figure 2: Example of neck remnant with subsequent coil compaction and aneurysm recanalization. Left, initial angiogram. Center, immediate posttreatment result, showing a small remnant and loose coil packing in the neck region. Right, follow-up angiogram six months later demonstrates compaction of the coils with substantial aneurysm recanalization. The patient subsequently was treated with surgical clipping.
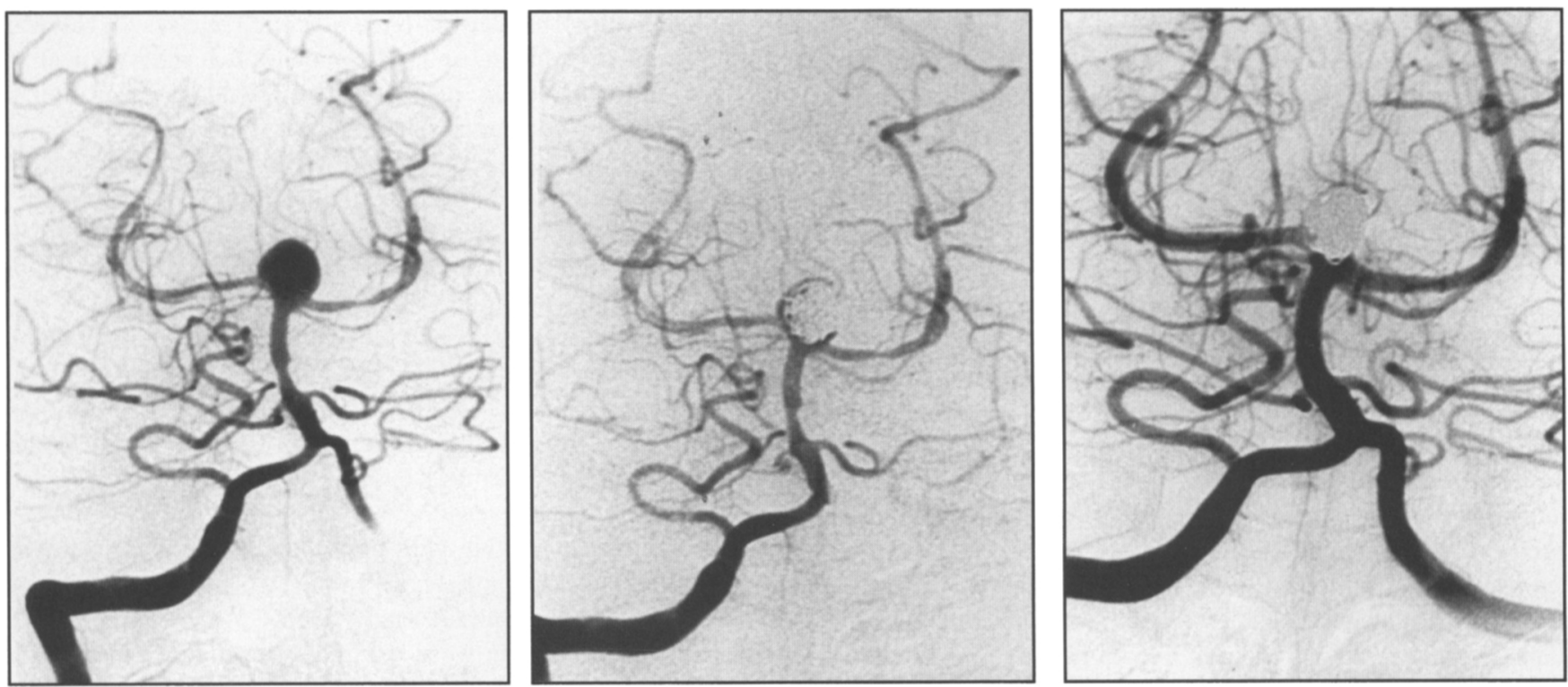

Figure 3: Incomplete aneurysm occlusion with eventual complete thrombosis. Left, initial angiogram. Center, immediate post-treatment result, showing subtotal aneurysm packing and obvious contrast filling around the periphery of the fundus. Dense packing of the aneurysm base was not possible because the aneurysm neck could not be completely separated from the posterior cerebral arteries despite imaging in multiple projections. Right, sixmonth follow-up angiogram shows no contrast filling around the coil mass. Dynamic rotational angiography confirmed complete aneurysm occlusion.

deficits $(7.5 \%)$, resulting from thrombo-embolic events in three cases (one followed by thrombolysis causing aneurysm rebleeding) and hemorrhage into a previous stroke in one. There were four procedural complications (10\%) which did not result in permanent deficits - one aneurysm perforation causing intraventricular hemorrhage, one minor stroke with rapid recovery, one TIA, and one episode of transient global amnesia. Overall procedural morbidity and mortality was therefore $20 \%$.

\section{Clinical Outcome}

Analysis of clinical outcome was limited to patients in whom coils were detached. Of the ten in whom treatment was unsuccessful, five with ruptured aneurysms underwent surgical clipping, two requiring hypothermic circulatory arrest. The five patients with unruptured aneurysms were referred back to their original neurosurgeon. Outcome status and long-term follow-up were not available for these patients, most of whom were managed at other institutions.

The group of patients in whom GDC treatment was successful included 19 females and 11 males, with a mean age of 52.5 years (range, 33 to 81 years). Twenty-three patients $(76.7 \%$ ) presented with SAH. Hunt and Hess grade at the time of treatment 

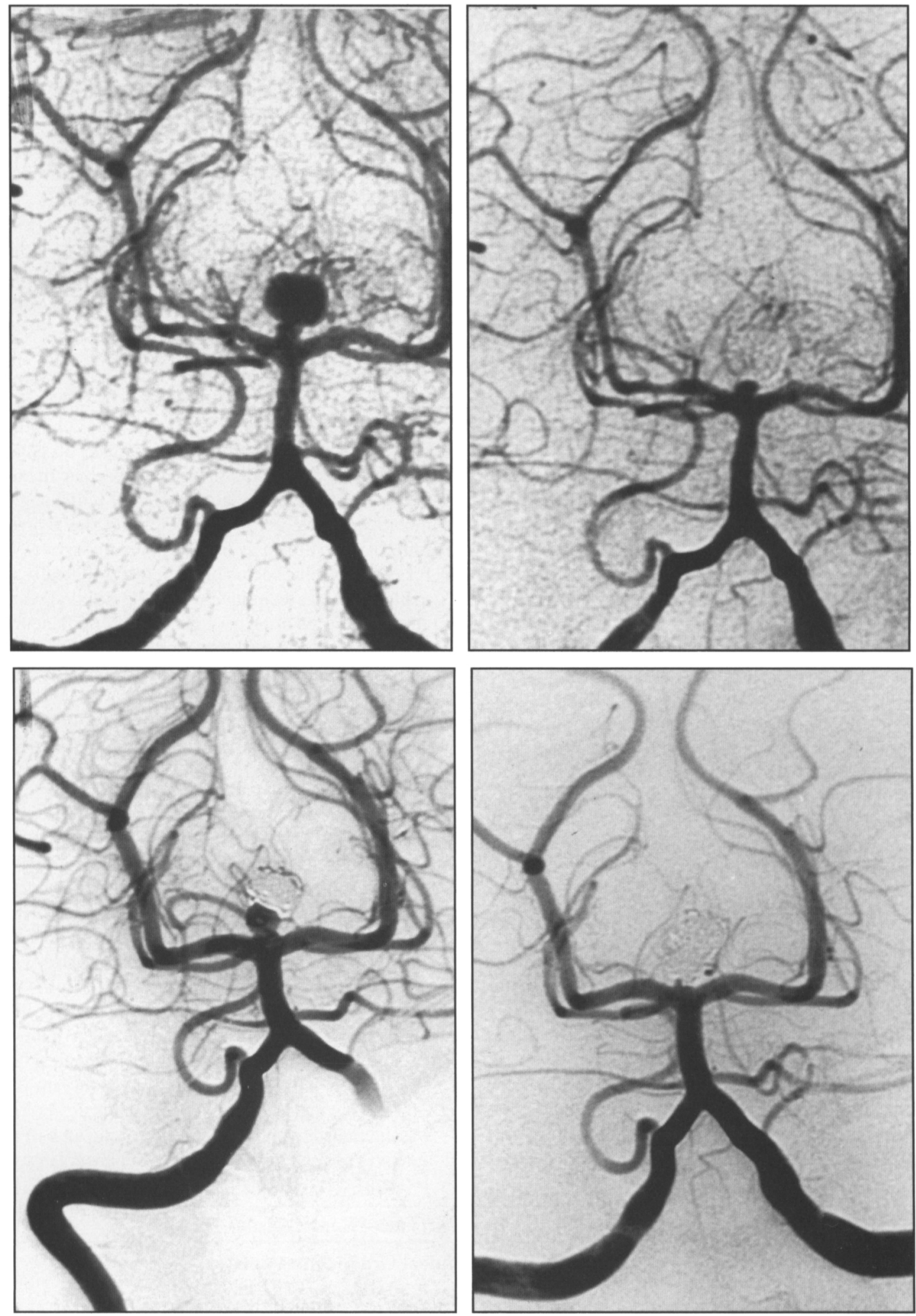

Figure 4: Aneurysm regrowth treated with repeat GDC packing. Upper left, initial angiogram demonstrates an unusual basilar tip aneurysm with a narrow elongated neck. In retrospect, this may have been a small aneurysm with formation of an adjacent pseudoaneurysm as a result of rupture. Upper right, immediate post-treatment angiogram demonstrates tight coil packing of the large, distal aneurysm component. Attempted coil placement into the small neck remnant resulted in herniation of coil loops into the upper basilar artery. Lower left, six-month follow-up angiogram demonstrates coil compaction and migration, with interval aneurysm recurrence. Lower right, angiogram demonstrating result of second GDC treatment. A neck remnant is present, smaller than after the initial procedure. Angiography will be repeated in six months. 


\begin{tabular}{|c|c|c|}
\hline Glasgow Outcome Scale & $\begin{array}{l}\text { Discharge } \\
N(\%)\end{array}$ & $\begin{array}{l}\text { Six Month Follow-up } \\
N(\%)\end{array}$ \\
\hline Good Recovery & $16(69.6)$ & $18(78.3)$ \\
\hline Moderate Disability & $3(13.0)$ & $2(8.7)$ \\
\hline Severe Disability & $2(8.7)$ & $1(4.3)$ \\
\hline Vegetative & 0 & 0 \\
\hline Dead & $2(8.7)$ & $(8.7)$ \\
\hline
\end{tabular}

was grade 1 in 10 cases $(33.3 \%)$, grade 2 in 4 cases $(13.3 \%)$, grade 3 in 6 cases (20\%), grade 4 in 2 cases $(6.7 \%)$, and grade 5 in one case $(3.3 \%)$. Two patients died following endovascular therapy, one as result of aneurysm rebleeding during attempted thrombolysis of a basilar artery occlusion, and one patient in grade 5 condition as a result of the initial bleed. The average length of clinical follow-up for the 28 surviving patients was 22 months (range 6 to 48 months).

The clinical outcome for all patients in whom coils were placed was graded according to the Glasgow Outcome Scale $(\mathrm{GOS}){ }^{28}$ All seven patients with unruptured aneurysms experienced excellent results, with no permanent morbidity and no late complications in the follow-up period. For the 23 patients with SAH, clinical outcome was recorded at the time of hospital discharge and at each follow-up visit. Clinical outcome at discharge and six months post-treatment is presented in Table 2. Overall outcome based on initial clinical grade is presented in Table 3. There were no episodes of aneurysm rebleeding following GDC treatment, and no late thrombo-embolic complications. No complications occurred in the two patients who underwent repeat endovascular therapy following coil compaction and aneurysm enlargement. One patient with SAH who made a good recovery after initial subtotal occlusion had coil compaction and aneurysm recanalization which required surgical clipping and was left in a moderately disabled condition.

\section{DISCUSSION}

In spite of considerable advances in microsurgical techniques and instrumentation, neuroimaging, and anesthesia, aneurysms arising at the terminal bifurcation of the basilar artery continue to pose a significant technical challenge. In particular, their intimate relation to vital brainstem perforating vessels and the oculomotor nerves in the confined space of the interpeduncular fossa makes operative management difficult. ${ }^{1-5}$ Although clinical outcome for surgical cases in experienced hands now approaches the results obtained for aneurysms in other locations, ${ }^{2,5}$ there is still considerable room for improvement in overall management outcome. ${ }^{3,4.8}$ The upper basilar artery is anatomically favorable for endovascular approaches, and if an incremental benefit in management-related morbidity and mortality for endovascular therapy over microsurgery is to be demonstrated, it should be most apparent in this location.

\section{Applicability of Endovascular Approaches to Basilar Bifurcation Aneurysms}

In this series of patients who were selected for endovascular therapy with GDC coils on the basis of their initial diagnostic angiogram, treatment was unsuccessful in $25 \%$ because of wide necks which allowed the coils to herniate into the parent vessel, or because of tortuous anatomy which prevented stable positioning of a microcatheter. This failure rate is higher than that reported in other series of basilar bifurcation aneurysms. ${ }^{18-24}$ Although a partial occlusion may have been possible in some of these cases, it was felt that definitive surgical clipping represented a better therapeutic option. The number of patients who were referred for consideration of endovascular therapy but rejected because of anatomical factors on their initial angiograms was not recorded; therefore, the $25 \%$ failure rate represents the lower limit of an estimate as to how many aneurysms were unsuitable for endovascular occlusion with electrolytically detachable coils using current techniques and devices. Treatment was not attempted in giant or partially thrombosed aneurysms, or in any aneurysms whose neck could not be defined on routine angiography or dynamic rotational studies. The posterior cerebral artery was not deliberately occluded, nor was the "balloon remodeling" ${ }^{29}$ technique employed in basilar bifurcation aneurysms during this time period. Both of these maneuvers increase the number of aneurysms which can be treated, but also add to procedural morbidity. ${ }^{19,29}$

\section{Degree and Permanence of Aneurysm Occlusion}

Although basilar tip aneurysms are anatomically straightforward to approach using endovascular techniques, the results of GDC occlusion are limited by the size and geometry of the sac and neck. Fernandez Zubillaga et al. ${ }^{30}$ reported that complete thrombosis could be achieved in $85 \%$ of aneurysms with a neck measuring $4 \mathrm{~mm}$ or less but in only $15 \%$ of aneurysms with larger necks. The importance of forming a three-dimensional "basket" with the first coils, occupying as much of the aneurysm sac as possible, is recognized as an important technical factor influencing the degree and permanence of aneurysm occlusion. ${ }^{11,12,30}$ Considering the 40 patients in this series in whom GDC treatment was attempted, complete occlusion at the time of the initial procedure was possible in $10(55.6 \%)$ of 18 aneurysms with small necks

Table 3: Clinical Outcome At Six Months Based on Clinical Grade at Time of Endovasacular Therapy.

\begin{tabular}{|c|c|c|c|c|c|c|c|}
\hline \multirow[b]{2}{*}{ Glasgow Outcome Scale } & \multicolumn{7}{|c|}{ Clinical Grade (Hunt \& Hess) } \\
\hline & Unruptured & $\mathbf{I}$ & II & III & IV & $\mathbf{V}$ & Total \\
\hline Good Recovery & 7 & 7 & 4 & 5 & 2 & 0 & 25 \\
\hline Moderate Disability & 0 & 2 & 0 & 0 & 0 & 0 & 2 \\
\hline Severe Disability & 0 & 0 & 0 & 1 & 0 & 0 & 1 \\
\hline Vegetative & 0 & 0 & 0 & 0 & 0 & 0 & 0 \\
\hline Dead & 0 & 1 & 0 & 0 & 0 & 1 & 2 \\
\hline Total No. of Patients & 7 & 10 & 4 & 6 & 2 & 1 & 30 \\
\hline
\end{tabular}


and $3(13.6 \%)$ of 22 with wide necks. All of the aneurysms that were completely occluded remained stable on follow-up angiography, while some degree of coil compaction and aneurysm refilling was common in those that were only partially treated.

Among the 30 patients in our series who had successful endovascular treatment of their aneurysm, complete occlusion was achieved at the time of initial treatment in $13(43.3 \%)$. Twelve of these patients have had follow-up angiography, with complete stability of the coil occlusion demonstrated in all cases. However, in patients with subtotal aneurysm occlusion, there was often evidence of coil compaction and increased contrast filling of the residual neck or aneurysm fundus. Follow-up angiography in 13 cases of incomplete coil packing demonstrated stability of the initial post-treatment appearance in $2(15.4 \%)$, deterioration in $9(69.2 \%)$, and improvement to complete aneurysm thrombosis in $2(15.4 \%)$. Repeat coil embolization was required in 2 cases, and surgical clipping performed in a third, because of coil compaction and aneurysm recanalization. All three of these cases required repeat treatment within 12 months of their initial procedure. There were no episodes of aneurysmal hemorrhage following complete or partial aneurysm occlusion, with an average length of clinical follow-up of 22 months.

The angiographic results obtained in our patients are comparable to other published series. Raymond et al..$^{24}$ reported on 31 patients with basilar bifurcation aneurysms treated with GDCs. Immediate post-treatment angiography demonstrated complete occlusion in $42 \%$. However, at the time of six-month control angiography, only $30 \%$ remained completely occluded. McDougall et al. ${ }^{21}$ described a series of 33 patients with basilar tip aneurysms in whom endovascular occlusion with GDC coils was attempted. Treatment was successful in 31 cases, with total occlusion accomplished initially in $7(21.2 \%)$. Nineteen of the patients underwent follow-up angiograms, at a mean of 11.7 months, with complete occlusion demonstrated in $4(21 \%)$. Residual filling of treated aneurysms increased in $10(53 \%)$ of the 19 patients in whom follow-up angiography was available. Guglielmi et al. ${ }^{18}$ reported on GDC treatment results in 43 posterior circulation aneurysms. Complete occlusion at the time of initial treatment was obtained in $5(21.7 \%)$ of 23 patients with basilar bifurcation aneurysms. Results of follow-up angiography 2 to 14 months post-treatment were reported for ten of these patients, with complete occlusion demonstrated in three. Pierot et al. ${ }^{23}$ described the angiographic results in 23 basilar bifurcation aneurysms treated with electrolytically or mechanically detachable platinum coils. Complete occlusion at the time of initial treatment was possible in $15(71.4 \%)$. Stability of total occlusion was shown in $7(53.8 \%)$ of 13 with follow-up angiography at an average of 6 months following the initial procedure.

\section{Complications Related to Endovascular Therapy}

The most common technical complications arising from endovascular aneurysm occlusion are caused by intraluminal thrombosis. In this series, intravascular clotting or presumed thrombo-embolic events occurred in 5 patients $(12.5 \%)$ in whom GDC treatment was attempted, despite systemic anticoagulation throughout the procedure. We did not routinely continue anticoagulation following coil placement, unless a loop of coil was observed to bulge into the parent vessel. An optimal anticoagulation protocol to reduce acute and delayed embolic events has been the subject of considerable discussion but is not resolved. ${ }^{13}$
It is important to note that there were no episodes of aneurysm bleeding related to systemic anticoagulation, despite the fact that a large bolus of heparin was administered during endovascular procedures prior to coil placement. Aneurysm rupture occurred in two cases, one as a result of mechanical perforation and one due to thrombolysis which was necessitated by basilar artery thrombosis. The latter complication is particularly dangerous. Successful thrombolysis in the basilar artery after endovascular occlusion of a recently ruptured basilar tip aneurysm has been reported, ${ }^{31}$ and fatal brainstem infarction is possible without dissolution of the clot, ${ }^{15}$ but direct intra-arterial thrombolytic treatment carries a high risk of causing recurrent hemorrhage in the acute stage of SAH.

\section{Clinical Outcome and Protection From Aneurysm Rupture}

Endovascular occlusion of aneurysms with GDC coils represents a substantial improvement in comparison to earlier techniques using balloons and free coils, with fewer procedural complications and better angiographic results. ${ }^{32}$ Analysis of perioperative and clinical outcomes in large reported series of endovascular therapy with GDC coils ${ }^{13,14,17}$ has shown that procedural risks and outcomes compare favorably to the International Cooperative Study on the Timing of Aneurysm Surgery, which evaluated medical and surgical management of patients with SAH between 1980 and $19833^{9,10}$ No prospective, randomized trials comparing surgical and endovascular therapy have been published. In a contemporary series, Richling et al. ${ }^{16}$ analyzed their experience in 220 patients with aneurysmal SAH of whom 137 were treated surgically and 83 were selected for treatment with GDCs. When stratified according to clinical grade and method of treatment, there was no significant difference in outcome between the surgical and endovascular groups.

In this series all patients with unruptured aneurysms had excellent outcomes. There was no permanent morbidity related to endovascular therapy, and no hemorrhages have occurred subsequently. Of 23 patients treated after aneurysm rupture, 18 (78.3\%) made a good recovery, $2(8.7 \%)$ were moderately disabled, $1(4.3 \%)$ was severely disabled, and $2(8.7 \%)$ died. Significant morbidity related to the procedure was one death $(2.5 \%)$ and three permanent neurological deficits $(7.5 \%)$. There were no cranial nerve palsies or brainstem perforator injuries, which are potential complications of surgical clipping of basilar bifurcation aneurysms. ${ }^{5}$ These complications do not necessarily preclude good outcomes, but add considerably to short-term morbidity and lengthen the time to recovery.

The ability of endovascular aneurysm occlusion with GDC coils to provide long-term protection against aneurysm rebleeding has not yet been addressed. The coils were first used clinically in 1990, ${ }^{11}$ and the longest reported follow-up is an average of 3.5 years. ${ }^{14}$ Our experience and that reported by others suggests that early rebleeding following complete occlusion in the acute phase of SAH is prevented. ${ }^{13,14,16,17.22 .24,33}$ However, most series report that complete aneurysm occlusion is achieved in less than half of all treated aneurysms, and the natural history of incompletely occluded aneurysms cannot be assumed to be benign. Fatal hemorrhages within 6 to 12 months of subtotal aneurysm occlusion have been described. $5,13,14,21$ The overall frequency of aneurysm rebleeding following endovascular occlusion, considering patients with complete and subtotal aneurysm occlusion, appears to be higher than what would be expected in surgically treated patients. 
Feuerberg et al. ${ }^{34}$ reported 715 patients with ruptured aneurysms clipped between 1970 and 1980, with an average follow-up of 8 years. All patients underwent early post-operative angiography. One aneurysm rest increased in size and bled, representing $3.7 \%$ of 27 patients in whom the aneurysm was not obliterated $(0.46 \%$ per year risk of hemorrhage for incompletely clipped aneurysms). The overall risk of recurrent hemorrhage following clipping of all aneurysms was $0.14 \%(0.017 \%$ per year $)$.

None of the patients in our series has experienced recurrent hemorrhage over an average period of follow-up of 22 months, but it is concerning that almost $70 \%$ of incompletely occluded aneurysms showed coil compaction and increased aneurysm filling on follow-up angiography. Three have required subsequent interventions, either repeat endovascular occlusion or surgical clipping, because of significant aneurysm regrowth. Others are being followed and may require further treatment in the future. Lin et al. ${ }^{35}$ described their experience with aneurysms that enlarged and bled following incomplete clipping. Nineteen aneurysms that had been clipped but which had small neck remnants presented with recurrent $\mathrm{SAH}$, at an average interval of 9 years after the initial surgery (range 3 to 24 years). The longest follow-up available for a series of patients with GDC coils is reported by Malisch et al., ${ }^{14}$ who evaluated 100 patients with a follow-up of 2 to 6 years. Seventy-three patients required only one procedure, 18 required two procedures, 8 required three procedures, and 1 patient required four procedures during this period. The incidence of recurrent aneurysm bleeding following GDC embolization was $0 \%$ for small aneurysms, $4 \%$ for large aneurysms, and $33 \%$ for giant aneurysms.

\section{Surgical or Endovascular Treatment: Clinical Considerations}

The primary goal of aneurysm treatment is to eliminate the risk of future hemorrhage. Following SAH, the risk of aneurysm rebleeding is very high within the first days, but rapidly tapers off after a few weeks. Individuals with untreated aneurysms who survive beyond 6 months have a risk of aneurysm rebleeding approximating $3 \%$ annually. ${ }^{36}$ Endovascular aneurysm occlusion with GDC coils appears to prevent acute rebleeding and has been accepted as a valuable alternative to surgical clipping when anatomical or medical factors significantly increase the operative risks. Many aneurysms are incompletely occluded, however, and the risks of hemorrhage in the future are not known. The value of "clinical cure" (subtotal aneurysm thrombosis) as opposed to "anatomical cure" (complete aneurysm obliteration) with respect to long-term prevention of bleeding remains to be established. For incompletely treated basilar bifurcation aneurysms, the water-hammer effect ${ }^{37}$ of pulsatile blood flow transmitted into the coil-thrombus complex may result in coil compaction or aneurysm regrowth, with potential for late rebleeding. It is likely that the risk of late rebleeding will be intermediate between the $0.46 \%$ per year risk reported by Feuerberg et al. ${ }^{34}$ for incompletely clipped aneurysms and the $3 \%$ per year risk of rebleeding in untreated "healed" aneurysms more than 6 months after SAH. $^{36}$

Our experience confirms that the best results of GDC treatment are achieved in small basilar bifurcation aneurysms with small necks. Aneurysms that are completely occluded at the time of initial treatment seem to remain stable on angiographic follow-up. These results are encouraging, and may support a man- agement strategy in which endovascular treatment is considered the primary method of dealing with aneurysms whose size and geometry are such that complete aneurysm occlusion is likely. Because clinical outcome from SAH is largely determined by clinical grade, it may be that patients with unruptured aneurysms or in good clinical grades will benefit most from the lower procedural and short-term morbidity associated with endovascular techniques.

Complete aneurysm occlusion and angiographic follow-up with repeat treatment of patients shown to have enlarging, incompletely treated aneurysms are essential to attain optimal clinical results. For large aneurysms or those with wide necks, this means that the cost and potential risks of multiple follow-up angiograms and possibly further endovascular or surgical procedures, as well as the small but real risk of recurrent hemorrhage, must be taken into consideration when deciding on initial treatment. Unfortunately, the giant sacs that are most difficult to manage surgically are generally the least suitable for endovascular coil obliteration. Combined surgical and endovascular procedures, in which partial clipping can be used to decrease aneurysm neck size so that coiling is feasible, or coils used to occlude aneurysm remnants following clipping, deserve consideration in the management of complex lesions. ${ }^{38-40}$

\section{Conclusions}

Endovascular occlusion of basilar bifurcation aneurysms with electrolytically detachable coils is a valuable alternative to microsurgical clipping in cases where anatomical or patient factors make surgical intervention particularly hazardous. Current limitations relate primarily to aneurysm size and geometry rather than location. Procedural complication rates compare favorably to surgery, and early aneurysm rebleeding appears to be reliably prevented. A minority of aneurysms can be completely occluded, however, and the long-term effectiveness of partial treatment remains to be established. Management will be most effectively carried out in centers with a team of cerebrovascular neurosurgeons and interventional neuroradiologists working in collaboration.

\section{ACKNOWLEDGEMENT}

Dr. Redekop was supported by a Detweiler Traveling Fellowship from the Royal College of Physicians and Surgeons of Canada.

\section{REFERENCES}

1. Batjer H, Samson D. Causes of morbidity and mortality from surgery of aneurysms of the distal basilar artery. Neurosurgery 1989; 25: $904-916$

2. Drake CG, Peerless SJ, Hernesniemi JA. Surgery of Vertebrobasilar Aneurysms, New York: Springer, 1996.

3. Hernesniemi J, Vapalahati M, Niskanen M, Kari A. Management outcome for vertebrobasilar artery aneurysms by early surgery. Neurosurgery 1992; 31: 857-862.

4. Hillman J, Saveland H, Jakobsson K, et al. Overall management outcome of ruptured posterior fossa aneurysms. J Neurosurg 1996; 85: 33-38.

5. Redekop GJ, Durity FA, Woodhurst WB. Management-related morbidity in unselected aneurysms of the upper basilar artery. J Neurosurg 1997; 87: 836-842.

6. Lang D, Galbraith SL. The management outcome of patients with a ruptured posterior circulation aneurysm. Acta Neurochir 1993; 125: 9-14. 
7. Saveland H, Brandt L. Which are the major determinants for outcome in aneurysmal subarachnoid hemorrhage? A prospective total management study from a strictly unselected series. Acta Neurol Scand 1994; 90: 245-250.

8. Schievink WI, Wijdicks E, Piepgras D, et al. The poor prognosis of ruptured intracranial aneurysms of the posterior circulation. J Neurosurg 1995; 82: 791-795.

9. Kassell NF, Torner JC, Haley EC, Jane JA, Adams HP. The international cooperative study on the timing of aneurysm surgery. Part 1: overall management results. J Neurosurg 1990; 73: 18-36.

10. Kassell NF, Torner JC, Haley EC, Jane JA, Adams HP. The international cooperative study on the timing of aneurysm surgery. Part 2: surgical results. J Neurosurg 1990; 73: 37-47.

11. Guglielmi G, Vinuela F, Dion J, Duckwiler G. Electrothrombosis of saccular aneurysms via endovascular approach, 2: preliminary clinical experience. J Neurosurg 1991; 75: 8-14.

12. Guglielmi G, Vinuela F, Sepetka I, Macellari V. Electrothrombosis of saccular aneurysms via endovascular approach, 1: electrochemical basis, technique, experimental results. J Neurosurg 1991; 75: $1-7$.

13. Cognard C, Weill A, Castaings L, Rey A, Moret J. Intracranial berry aneurysms: angiographic and clinical results after endovascular treatment. Radiology 1998; 206: 499-510.

14. Malisch T, Guglielmi G, Vinuela F, et al. Intracranial aneurysms treated with the Guglielmi detachable coil: midterm clinical results in a consecutive series of 100 patients. J Neurosurg 1997; 87: 176-183.

15. Nichols DA. Endovascular treatment of the acutely ruptured intracranial aneurysm. J Neurosurg 1993; 79: 1-2.

16. Richling B, Bavinski G, Gross C, Gruber A, Killer M. Early clinical outcome of patients with ruptured cerebral aneurysms treated by endovascular (GDC) or microsurgical techniques. A single center experience. Intervent Neuroradiol 1995; 1: 19-27.

17. Vinuela F, Duckwiler G, Mawad M. Guglielmi detachable coil embolization of acute intracranial aneurysm: perioperative anatomical and clinical outcome in 403 patients. J Neurosurg 1997; 86: 475-482.

18. Guglielmi G, Vinuela F, Duckwiler G, et al. Endovascular treatment of posterior circulation aneurysms by electrothrombosis using electrically detachable coils. J Neurosurg 1992; 77: 515-524.

19. Klein GE, Hausegger KA, Karaic R, Leber KA, Szolar DH. Basilar tip aneurysm: endovascular treatment with Guglielmi detachable coils - midterm results. Radiology 1997; 205; 191-196.

20. Massoud TF, Guglielmi G, Vinuela F, Duckwiler G. Endovascular treatment of multiple aneurysms involving the posterior circulation. Am. J. Neuroradiol 1996; 17: 549-554.

21. McDougall C, Halbach V, Dowd C, et al. Endovascular treatment of basilar tip aneurysms using electrolytically detachable coils. J Neurosurg 1996; 84: 393-399.

22. Nichols D, Brown R, Thielen K, et al. Endovascular treatment of ruptured posterior circulation aneurysms using electrolytically detachable coils. J Neurosurg 1997; 87: 374-380.

23. Pierot L, Boulin A, Castaings L, Rey A, Moret J. Selective occlusion of basilar artery aneurysms using controlled detachable coils: report of 35 cases. Neurosurgery 1996; 38: 948-953.
24. Raymond J, L'Esperance G, Moumdjian R, Bojanowski M, Roy D. Endovascular treatment of acutely ruptured and unruptured aneurysms of the basilar bifurcation. J Neurosurg 1997; 86: 211219.

25. Eskridge JM, Song JK, and the Participants. Endovascular embolization of 150 basilar tip aneurysms with Guglielmi detachable coils: results of the Food and Drug Administration multicenter clinical trial. I Neurosurg 1998; 89: 81-86.

26. Hunt WE, Hess RM. Surgical risk as related to time of intervention in the repair of intracranial aneurysms. J Neurosurg 1968; 28: 1420.

27. Hoff DJ, Wallace MC, TerBrugge KG, Gentili F. Rotational angiography assessment of cerebral aneurysms: Am J Neuroradiol 1994; 15: 1945-1948.

28. Jennett B, Bond M. Assessment of outcome after severe brain damage. A practical scale. Lancet 1975; 1: 480-484.

29. Moret J, Cognard C, Weill A, Castaings L, Rey A. The "remodelling technique" in the treatment of wide neck intracranial aneurysms. Intervent Neuroradiol 1997; 3: 21-35.

30. Fernandez Zubillaga A, Guglielmi G, Vinuela F, Duckwiler G. Endovascular occlusion of intracranial aneurysms with electrically detachable coils: correlation of aneurysm neck size and treatment results. Am J Neuroradiol 1994; 15: 815-820.

31. Kwan ES, Kwon OJ, Borden JA. Successful thrombolysis in the vertebrobasilar artery after endovascular occlusion of a recently ruptured large basilar tip aneurysm. Am J Neuroradiol 1995; 16: 847-851.

32. Picard L, Bracard S, Lehericy S, et al. Endovascular occlusion of intracranial aneurysms of the posterior circulation: comparison of balloons, free coils, and detachable coils in 38 patients. Neuroradiology 1996; 38 (Suppl. 1): S133-S141.

33. Graves VB, Strother CM, Duff TA, Perl J. Early treatment of ruptured aneurysms with Guglielmi detachable coils: effect on subsequent bleeding. Neurosurgery 1995; 37: 640-647.

34. Feuerberg I, Lindquist C, Lindquist M, Steiner L. The late consequences of incomplete surgical treatment of cerebral aneurysms. J Neurosurg 1987; 66: 30-34.

35. Lin T, Fox A, Drake C. Regrowth of aneurysm sacs from residual neck following aneurysm clipping. J Neurosurg 1989; 70: 556560.

36. Jane JA, Winn HR, Richardson AE. The natural history of intracranial aneurysms: rebleeding rates during the acute and long term period and implication for surgical management. Clin Neurosurg 1977; 24: 176-184.

37. Kwan E, Heilman C, Shucart W, Klucznik R. Enlargement of basilar artery aneurysms following balloon occlusion - "water-hammer effect". J Neurosurg 1991; 75: 963-968.

38. Fraser KW, Halbach VV, Teitelbaum GP, et al. Endovascular platinum coil embolization of incompletely surgically clipped cerebral aneurysms. Surg Neurol 1994; 41: 4-8.

39. Marks M, Steinberg G, Lane B. Combined use of endovascular coils and surgical clipping for intracranial aneurysms. Am J Neuroradiol 1995; 16: 15-18.

40. Thielen KR, Nichols DA, Fulgham JR, Piepgras DG. Endovascular treatment of cerebral aneurysms following incomplete clipping. J Neurosurg 1997; 87: 184-189. 